\title{
GENERALIZED FIRST ORDER DYNAMIC EQUATIONS ON TIME SCALES WITH $\triangle$-CARATHÉODORY FUNCTIONS
}

\author{
SANKET TIKARE
}

Abstract. In this paper we consider a first order dynamic equation on time scales in which the right hand side is a $\Delta$-Carathéodory function, which is not necessarily continuous. We generalize this discontinuous dynamic equation using Henstock-Kurzweil $\Delta$-integral and establish results concerning existence of solutions using simple analysis. Uniqueness of solutions is obtained using an Osgood type condition. Moreover we introduce the concept of Henstock-Kurzweil $\Delta$-equi-integrability and study continuous dependence and convergence of solutions.

Mathematics subject classification (2010): 26A39, 34A12, 34A26, 34N05.

Keywords and phrases: Henstock-Kurzweil integral, dynamic equations, time scales, Carathéodory's type solution.

\section{REFERENCES}

[1] B. Bayour, A. Hammoudi And D. Torres, Existence of solution to a Nonlinear-First Order Dynamic Equations on Time Scales, J. Math. Anal. 7, 1 (2016), 31-38.

[2] M. Bohner And A. C. Peterson, Dynamic Equations on Time Scales: An Introduction with Applications, Birkhäuser, Boston, 2001.

[3] M. Bohner And A. C. Peterson, Advances in Dynamic Equations on Time Scales, Birkhäuser, Boston, 2004.

[4] L. Bourlin and E. Trélat, General Cauchy-Lipschitz. Theory for $\Delta$-Cauchy Problems with Carathéodory Dynamics on Time Scales, J. Differ. Equ. Appl. 20, 4 (2014), 526-547.

[5] A. CABADA AND D. R. Vivero, Expression of the Lebesgue $\Delta$-Integral on Time Scales as a usual Lebesgue Integral: Application to the Calculus of $\Delta$ Antiderivatives, Math. Comput. Modelling 43, 1-2 (2006), 194-207.

[6] T. S. Chew And F. Flordeliza, On $x^{\prime}=f(t, x)$ and Henstock-Kurzweil Integrals, Differ. Integral Equ. 4, 4 (1991), 861-868.

[7] M. Cichoń, I. Kubiaczy K, A. Sikorska-Nowak And A. YAntiR, Existence of Solutions of the Dynamic Cauchy Problems in Banach Spaces, Demonstratio Math. 45, 3 (2012), 561-573.

[8] E. A. Coddington And N. Levinson, Theory of Ordinary Differential Equations, Tata McGraw Hill Book Co., New Delhi, 2000.

[9] Q. Dai And C. C. Tisdell, Existence of Solutions to First Order Dynamic Boundary Value Problems, Int. J. Difference Equ., vol. 1, 1 (2006), 1-17.

[10] A. Deniz, Measure Theory on Time Scales, Master of Science Thesis, İzmir Institute of Technology, Turkey, Jan. 2007.

[11] J. DiBlík, M. RÅUŽIČKovÁ And B. VÁClaViková, Bounded Solutions of Dynamic Equations on Time Scales, Int. J. Difference Equ. 3, 1 (2008), 61-69.

[12] H. Gilbert, Existence Theorems for First-Order equations on Time Scales with $\Delta$-Carathéodory Functions, Adv. Difference Equ. 2010, (2010) Article ID 650827, 20 pages.

[13] G. S. Guseinov, Integration on Time Scales, J. Math. Anal. Appl. 285, (2003), 107-127.

[14] S. Hilger, Analysis on Measure Chains - a Unified Approach to Continuous and Discrete Calculus, Results Math., 18, 1-2 (1990), 18-56.

[15] I. KubiacZYK AND A. SikorSKa-NowaK, Existence of Solutions of the Dynamic Cauchy Problem on Infinite Time Scale Intervals, Dis. Math. DICO 29, (2009), 113-126. 
[16] A. C. Peterson And C. C. Tisdell, Boundedness and Uniqueness of Solutions to Dynamic Equations on Time Scales, J. Differ. Equ. appl. 10, 13-15 (2004), 1295-1306.

[17] A. C. Peterson And B. Thompson, Henstock-Kurzweil Delta and Nabla Integrals, J. Math. Anal. Appl. 323, (2006), 162-178.

[18] I. L. D. Santos, Discontinuous Dynamic Equations on Time Scales, Rend. Circ. Mat. Palermo 64, 3 (2015), 383-402.

[19] B. Satco, A Cauchy Problem on Time Scales with Applications, An. Stiint. Univ. Al. I. Cuza Iasi. Mat. (N. S.) Matematica, Tomul LVII, (2011), Supliment, 221-234.

[20] B. SATCO, Dynamic Equations on Time Scales seen as Generalized Differential Equations, Bulletin of the Transilvania University of Brasov Series III: 5, 54 (2012), 247-258.

[21] A. Slavír, Dynamic equations on Time Scales and Generalized Ordinary Differential Equations, J. Math. Anal. Appl. 385, (2012), 534-550.

[22] B. S. Thomson, Henstock-Kurzweil Integrals on Time Scales, Panamer. Math. J. 18, 1 (2008), 1-19. 